\title{
Seroprevalence of Chlamydia trachomatis infection among pregnant women and their outcome
}

\author{
Vibha Rani Pipal ${ }^{1 *}$, Rajendra Pipal², Dharmendra Pipal ${ }^{3}$, Seema Yadav4, \\ Manoj Kamal ${ }^{5}$, Geeta Singariya ${ }^{6}$
}

\author{
${ }^{1}$ Department of Obstetrics and Gynecology, C. B. Hospital, Jodhpur, Rajasthan, India \\ ${ }^{2}$ Department of Orthopaedics, C. B. Hospital, Jodhpur, Rajasthan, India \\ ${ }^{3}$ Department of General Surgery, Dr. Sampurnanand Medical College, Jodhpur, Rajasthan, India \\ ${ }^{4}$ Department of Anaesthesiology, C. B. Hospital, Jodhpur, Rajasthan, India \\ ${ }^{5}$ Department of Anaesthesiology, AIIMS, Jodhpur, Rajasthan, India \\ ${ }^{6}$ Department of Anaesthesiology, Dr. Sampurnanand Medical College, Jodhpur, Rajasthan, India
}

Received: 12 January 2017

Accepted: 08 February 2017

\section{*Correspondence:}

Dr. Vibha Rani Pipal,

E-mail: ranigkpvibha@gmail.com

Copyright: ( the author(s), publisher and licensee Medip Academy. This is an open-access article distributed under the terms of the Creative Commons Attribution Non-Commercial License, which permits unrestricted non-commercial use, distribution, and reproduction in any medium, provided the original work is properly cited.

\section{ABSTRACT}

Background: Genitourinary infections either sexually transmitted or by other means are a major concern among women, particularly young adults and teens. The objective was to find out seroprevalence of Chlamydia trachomatis infection in pregnant women and its effect on pregnancy outcome.

Methods: the present study was carried out in the department of obstetrics and gynaecology, King George Medical University of Lucknow, Uttar Pradesh, India, over a period of September 2003 to July 2004. Total 120 pregnant women were included in the study, these pregnant women were selected according to their will in taking part in the study irrespective of age and parity. $2 \mathrm{ml}$ of blood sample was collected and determination of antichlamydial IgM antibody was done by VIRCELL SL IgM ELISA Kit in microbiology department. Prevalence of chlamydia trachomatis in pregnant women were assessed and correlated with age group, parity, socioeconomic status, previous obstetric outcome, anaemia, PROM, mode of termination according to gestational age, perinatal outcome regards birthweight, and adverse neonatal outcome.

Results: Out of 120 cases, total $70(58.33 \%)$ were positive while the remaining 50 cases were negative. 80 cases were followed till delivery in which $66.25 \%$ were positive for antichlamydial IgM antibody. There was significant association of previous history of 2-3 abortion and preterm delivery with IgM positive cases. Low birth weight deliveries were $78 \%$ and very low birth weight was $100 \%$ in positive cases. Caesarean section at $<37$ weeks of gestation, IUGR and low APGAR score were significantly high in IgM positive group. 100\% PROM cases were IgM positive.

Conclusions: The prevalence of chlamydia trachomatis infection among pregnant women in our population is high and is strongly associated with premature rupture of membranes, IUGR, LBW, and low APGAR score deliveries.

Keywords: Antichlamydial IgM antibody, APGAR score, Chlamydia trachomatis, IUGR, LBW babies, PROM, VIRCELL SL IgM ELISA Kit 


\section{INTRODUCTION}

Genitourinary infections either sexually transmitted or by other means are a major concern among women, particularly young adults and teens. chlamydia trachomatis infection is probably the most common sexually transmitted infection in both females and males. Chlamydia trachomatis has been extensively studied because of its association with ocular trachoma and its prevalence as a sexually transmitted pathogen. ${ }^{1}$ Chlamydia is an obligate intracellular parasite with a unique bipolar life cycle. They are classified in the order clamydiales, one family, chlamydiacae, and genus chlamydia. Within this genous four species are recognised currently, c. Pecorum, c. trachomatis, c. Pittaci, c. Pneumonae. Chlamydia trachomatis is further classified on serological basis in 15 serotypes. Serotype 11, 1-2, 1-3 causes lymphogranuloma venereum (LGV). Serotype-A, B, Ba and C cause trachoma, the remaining $\mathrm{D}, \mathrm{E}, \mathrm{F}, \mathrm{G}, \mathrm{H}, \mathrm{I}, \mathrm{J}, \mathrm{K}$ serotypes are the causative agents in occulogenital and sexually transmitted infections like epididymitis, new-born pneumonia and perinatal infections. Chlamydia has a complex biphasic lifecycle. ${ }^{1}$ In extracellular form the elementary body attaches to susceptible epithelial cells and enters by phagocytosis, pinocytosis or receptor mediated endocytosis. ${ }^{2}$ The intracellular reticulate body, is the replicative form which divides and form a cytoplasmic inclusion body with its progeny and glycogen multiply by binary fission. They divide in approximating 8-24 hours and then condensed to form new elementary bodies. As the numbers of elementary bodies increases for 48-72 hours, the host cell bursts and liberate these infective parasites. The complete infective cycle takes 2-3 days.

The primary method of transmission is sexual, the most commonly infected anatomic site is cervix. Most of the chlamydial cervicitis is asymptomatic but careful speculum examination reveals evidence of mucopurulent cervicitis. Symptomatic women may present with dysurea, sterile pyuria intermenstrual or postcoital bleeding.

The reported prevalence of $C$. trachomatis infection in sexually active women is $20-40 \%$ approximately $3-5 \%$ in non-pregnant women and $2-30 \%$ in pregnant women., ${ }^{2,3}$ Infants of women colonised with $C$. trachomatis are having $60-70 \%$ risk of becoming colonised during birth. ${ }^{4}$ This has associated with poor obstetric outcome like stillbirth, preterm delivery, PROM, and LBW deliveries.

In India, few hospital based studies have shown prevalence of $C$. trachomatis infection from $3.3 \%$ to $35.91 \% .^{6}$

The present study is undertaken to find out the prevalence of chlamydia trachomatis infection based on detection of antichlamydial antibodies in pregnant women and its association with the pregnancy outcome.

\section{METHODS}

Total 120 pregnant women were included in present study. Their detailed history regarding previous obstetric outcome, socioeconomic status, discharge per vagina and previous treatment for STI of them and in their partner asked. General, systemic and local examination, per speculum and per vaginal examination performed. With routine investigations, $2 \mathrm{ml}$ of blood sample was collected from antecubital vein in a sterile vial and transferred within 2 hours to the department of microbiology, where serum was separated and stored at $20^{\circ} \mathrm{C}$ till use.

Pregnant woman with history suggestive of genitourinary infection or her partner, previous antibiotic treatment for such infection prior to 8 weeks of enrollment and history of chronic illness like diabetes mellitus, chronic heart disease, hypertension, VDRL positive cases were excluded.

Determination of antichlamydial IgM antibody done by VIRCELL SL IgM ELISA kit. The entire ELISA procedure, calculation of antibody index and interpretation of result was performed. All deliveries were attended by paediatrician. The birth weight was recorded on an electronic weighing scale. Neonatal outcome in terms of birth weight, APGAR score, morbidity and mortality after birth were recorded. where applicable chi-square test was applied.

\section{RESULTS}

Table 1 shows total 120 cases with their time of enrollment and prevalence of c. Trachomatis on the basis of ELISA IgM test. A total of $70(58.33 \%)$ cases, out of 120 were positive.

Follow-up was possible in 80 women who delivered in the hospital. All women were between age 20-37 years. No significant correlation was found regarding age, parity and socioeconomic status and degree of anaemia between $\operatorname{IgM}$ positive and $\operatorname{IgM}$ negative cases in the study.

Table 2 shows out of 120 cases 25 (20.83\%) has history of single or multiple abortions in past, out of which 16 $(64 \%)$ were positive for IgM, in these $10(55.6 \%)$ has single abortion $(\mathrm{p}=0.50)$ and $6(100 \%)$ had $2-3$ abortion $(\mathrm{p}<0.001)$. So, there were statistical correlation of previous 2-3 abortion with IgM positivity.

Table 3 shows that out of 120 cases, 80 cases followed till termination. One case of history of previous three abortion was registered at 16 weeks of gestation and the pregnancy had to be terminated for missed abortion was IgM negative. Another case had stillbirth at 28 weeks of gestation and was IgM positive. 
Out of 66 cases, $41(51.25 \%)$ had FTND in which $61 \%$ were IgM positive, $22(27.5 \%)$ had FT LSCS, in which approximately $68 \%$ were $\operatorname{IgM}$ positive and $3(3.75 \%)$ had instrumental delivery in which one case $(33.3 \%)$ was $\operatorname{IgM}$ positive.
In 12 preterm delivery cases, 3 (100\% IgM positive) has vaginal delivery and $9(11.25 \%)$ had LSCS in which 8 cases $(88.8 \%)$ were $\operatorname{IgM}$ positive $(\mathrm{p}<0.001)$. So, IgM positive were high in cases with preterm deliveries.

Table 1: Seroprevalence of $C$. trachomatis in cases according to the trimester of enrolment.

\begin{tabular}{|lllllll|}
\hline Time of visit & Total no of cases & Positive & \multicolumn{4}{c|}{ Negative } \\
& No & $\mathbf{\%}$ & No & \% & Equivocal \\
\hline 1st trimester & 01 & 01 & 100 & 0 & 0 & \\
\hline 2nd trimester & 42 & 25 & 59.52 & 16 & 38.09 & $1(2.38 \%)$ \\
\hline 3rd trimester & 77 & 44 & 57.14 & 30 & 38.96 & $3(3.84 \%)$ \\
\hline
\end{tabular}

Table 2: C. trachomatis infection in relation to previous obstetrics outcome and statistical correlation.

\begin{tabular}{|c|c|c|c|c|}
\hline \multirow[t]{2}{*}{ Previous outcome } & \multirow[t]{2}{*}{ Total $(n=120)$} & \multicolumn{2}{|c|}{ IgM - antibody } & \multirow[t]{2}{*}{ p-value } \\
\hline & & Positive & Negative & \\
\hline Abortion & $25(20.83 \%)$ & $16(64 \%)$ & $09(36 \%)$ & \\
\hline Single & $18(15 \%)$ & $10(55.6 \%)$ & $08(44.4 \%)$ & 0.50 \\
\hline $2-3$ & $06(5 \%)$ & $06(100 \%)$ & & $<0.001$ \\
\hline$>3$ & $01(0.83 \%)$ & & $01(100 \%)$ & 0.64 \\
\hline Ectopic & $02(1.7 \%)$ & & $02(100 \%)$ & $<0.05$ \\
\hline
\end{tabular}

Table 3: Correlation of $C$. Trachomatis infection with mode of termination according to gestational age.

\begin{tabular}{|c|c|c|c|c|c|c|c|c|c|c|}
\hline \multirow{3}{*}{$\begin{array}{l}\text { Mode of } \\
\text { termination }\end{array}$} & \multicolumn{5}{|c|}{ Term } & \multicolumn{5}{|c|}{ Preterm } \\
\hline & \multirow{2}{*}{ Total } & \multicolumn{2}{|c|}{ IgM positive } & \multicolumn{2}{|c|}{ IgM negative } & \multirow{2}{*}{ Total } & \multicolumn{2}{|c|}{ IgM positive } & \multicolumn{2}{|c|}{ IgM negative } \\
\hline & & No. & $\%$ & No. & $\%$ & & No. & $\%$ & No. & $\%$ \\
\hline Normal delivery & & & & & & 3 & & & & \\
\hline Single & $41(51.25 \%)$ & 25 & 61 & 16 & 39 & 2 & 2 & 100 & - & - \\
\hline Twin & - & - & - & - & - & 1 & 1 & 100 & - & - \\
\hline Caesarian section & $22(27.5 \%)$ & & & & & 9 & & & & \\
\hline Single & 21 & 14 & 66.66 & 7 & 32 & 8 & 7 & 87.5 & 1 & 12.5 \\
\hline Twin & 1 & 1 & 100 & - & - & 1 & 1 & 100 & - & - \\
\hline Instrumental delivery & $3(3.75 \%)$ & 1 & 33.3 & 2 & 66.7 & - & - & - & - & - \\
\hline
\end{tabular}

MTP- 1 (16 weeks) IgM negative, Stillbirth- 1 (28 weeks) IgM positive.

Table 4: Correlation of $C$. trachomatis with premature rupture of membrane (PROM).

\begin{tabular}{|lllll|}
\hline PROM cases & Chlamydia IgM & Mode of delivery & Baby weight $(\mathrm{Kg})$ & APGAR score \\
\hline 1 & positive & CS & 1.5 & $8,9,10$ \\
\hline 2 & positive & ND & 2.75 & $8,9,10$ \\
\hline 3 & positive & ND & 3.01 & $7,8,9$ \\
\hline 4 & positive & CS & 2.75 & $7,8,9$ \\
\hline
\end{tabular}

Table 5: Correlation of $C$. trachomatis and birth weight $(\mathrm{N}=80)$.

\begin{tabular}{|lllllll|}
\hline \multirow{2}{*}{ Weight(kg) } & Total & \multicolumn{3}{c}{ IgM positive } & \multicolumn{3}{c|}{ IgM negative } \\
\cline { 2 - 8 } & No & $\%$ & No & $\%$ & No & $\%$ \\
\hline$\geq 2.5$ & 61 & 76.25 & 39 & 63.9 & 22 & 37.06 \\
\hline $1.5-2.4$ (low) & 17 & 21.25 & 13 & 76.4 & 04 & 23.52 \\
\hline$<1.5$ (very low) & 01 & 1.25 & 01 & 100 & - & - \\
\hline 100 gm (MTP) & - & - & - & - & 1 & 100 \\
\hline
\end{tabular}


Table 6: Newborn outcome.

\begin{tabular}{|lllll|}
\hline & Number & IgM positive & IgM negative & P-value \\
\hline LBW (18) & 18 & $14(77.77 \%)$ & $4(22.22 \%)$ & $<0.001$ \\
\hline Apgar score (<7 at 1min) & 4 & $4(100 \%)$ & - & $<0.05$ \\
\hline Transient tachypnoea & 8 & $6(75 \%)$ & $2(25 \%)$ & 0.1 \\
\hline Pathological jaundice & - & - & - & - \\
\hline Purulent conjuctivitis & 2 & $2(100 \%)$ & - & 0.15 \\
\hline
\end{tabular}

Table 4 shows among 120 cases 4 cases $(3.33 \%)$ had PROM and all $(100 \%)$ were IgM positive, out of them 2 had LSCS and 2 had normal delivery. Out of two caesarean one baby was small for gestational age of 1.5 kg. Hence Chlamydia trachomatis has definitive correlation with PROM.

As per Table 5, among 80 cases followed, one case was 16 weeks missed abortion (IgM negative) was terminated, foetus weight was $100 \mathrm{gm}$, one case had 28 weeks' stillbirth and foetal weight was $1.5 \mathrm{~kg}$ (IgM positive). 61 cases had babies weighing $2.5 \mathrm{~kg}$ and more, out of which $39(63.9 \%)$ were IgM positive and $22(36.06 \%)$ were $\operatorname{IgM}$ negative.

$17(21.25 \%)$ had babies weighing $<2.5 \mathrm{~kg}$ in which 13 (76.4\%) were positive. LBW babies were high in positive than negative group.

Table 6 shows, out of 18 LBW babies, $14(77.77 \%)$ were from $\operatorname{IgM}$ positive mothers and $4(22,22 \%)$ were from IgM negative mothers. So LBW was significantly higher in IgM positive mothers $(\mathrm{p}<0.001)$. low apgar score babies were $4(100 \%)$ in $\operatorname{IgM}$ positive mothers $(\mathrm{p}<0.05)$. occurences of transient tachypnoea $(\mathrm{p}=0.1)$ and purulent conjunctivitis $(\mathrm{p}=0.15)$ were also found to be high in $\operatorname{IgM}$ positive mothers.

\section{DISCUSSION}

chlamydia trachomatis is found worldwide and is probably the most common sexually transmitted infection. The organism is responsible for variety of infections in women like cervicitis, endometritis, acute urethral syndrome and salpingitis. ${ }^{1}$

In present study, out of 120 cases $70(58.33 \%)$ were IgM positive i.e. there was high prevalence in pregnant women irrespective of age, parity, socioeconomic status and degree of anaemia. Jain et al reported $35.9 \%$ prevalence in asymptomatic pregnant women, Rastogi and Salhan et al found $21.3 \%$ and Yashodhara $\mathrm{P}$ et al showed $29.3 \%$ prevalence. $^{6-8}$

In this study there was positive correlation of $C$. trachomatis infection with history of previous 2-3 abortions $(100 \%, \mathrm{p}<0.001)$, no significant correlation were found with history of single or $>3$ abortions, ectopic pregnancy. The correlation of spontaneous abortion and C. trachomatis infection were $15.6 \%$ by Rastogi and Salhan et al, $46.5 \%$ by Kishore $\mathrm{J}$ et al and $26 \%$ by Avasthi et al. ${ }^{7,9,10}$

In present study out of 80 cases followed till termination, 66 had full term delivery in which $62 \%$ were IgM positive and 12 had preterm delivery in which $92 \%$ were IgM positive in both vaginal deliveries and LSCS at $<37$ weeks of gestational age. One case was $\operatorname{IgM}$ negative $(\mathrm{p}<0.001) 16$ weeks missed abortion, and one case was IgM positive 28 weeks' stillbirth. So, preterm delivery were high $(\mathrm{p}<0.001)$ among IgM positive cases. Martius et al had shown positive association of $C$. tracomatis infection (odd ratio 3.9) with preterm birth.

Rastogi and Kapur showed increased incidence of stillbirth prematurity (16.6\% vs $5.7 \%, 26.6 \%$ vs $18.4 \%){ }^{7}$ Yashodhara $\mathrm{P}$ et al had shown positive correlation between seropositivity and adverse outcome i.e. preterm deliveries, PROM, stillbirth $(34.7 \%$ vs $10.7 \%$, p<0.001).

In this study PROM cases were IgM positive. Study of Richard L et al had reported incidence of PROM 54.6\% in positive cases. Yashodhara $\mathrm{P}$ et al showed $26.08 \%$ incidence of PROM in positive cases. ${ }^{11}$ Present study showed out of LBW deliveries $77.77 \%$ were in IgM positive mothers.

Study of Jain A et al showed occurrence of LBW babies in $28.7 \%$ IgM positive mothers, Rastogi and Kapur et al also found an increased incidence of LBW babies in chlamydia positive cases as compare to negative $(26.6 \%$ vs $23.0 \%$, p<0.05).

Low apgar score, transient trachypnoea, purulent conjunctivitis were found to be high in $\operatorname{IgM}$ positive mothers.

Paul VK et al showed $12.5 \%$ incidence of purulent conjunctivitis and transient tachypnoea in chlamydia positive mothers. ${ }^{12}$

\section{CONCLUSION}

Chlamydia trachomatis has currently emerged as the most common sexually transmitted pathogen. It is usually asymptomatic and is difficult to diagnose clinically. 
The present study showed $58.33 \%$ prevalence of $C$. trachomatis infection in pregnant women. The IgM seropositive rate was high among mothers with PROM $(100 \%)$, still birth, preterm LBW babies and in neonatal outcome; low apgar score, transient tachypnoea and purulent conjunctivitis. Therefore, from this study it has been concluded that there is high prevalence of chlamydia trachomatis infection among women in our population irrespective of age, gestational age, parity and socioeconomic status. there is strong association with preterm deliveries, LBW babies and low apgar score deliveries in chlamydia positive women.

So this study suggests that routine screening of pregnant women should be done for antichlamydiaa IgM and should be treated, that will help in reducing the adverse effect of obstetric outcome.

Funding: No funding sources

Conflict of interest: None declared

Ethical approval: The study was approved by the Institutional Ethics Committee

\section{REFERENCES}

1. Robert B. Jones, Byron E. Mandell, Douglas, and Bennett's Principles and Practice of Infectious Diseases, 5th Ed. 2000;2A(168):1989-2004.

2. Schachter J, Dawson CR. Human chlamydial trachomatis infections. in: PSG Publishing Co. Littleton, Massachusetts; 1978:63-96.

3. Heggie AD, Lumicao GG, Stuart LA, Gyves MT. Chlamydia trachomatis infection in mothers and infants. A prospective study. Am J Dis Child. 1981;135(6):507-11.

4. Martius J, Krohn MA, Hillier SL, Stamm WE, Holmes KK, Eschenbach DA. Relationships of vaginal lactobacillus species, cervical chlamydia trachomatis and bacerial vaginosis to preterm birth. Obstet Gynaecol. 1988;71:89-95.
5. Rastogi S, Das B. Serum IgM to Chlamydia trachomatis in pregnancy; its usefulness for screening. Br J Bio Med Sci. 2002;59(1):30-4.

6. Alexander ER, Harrison HR. Role of Chlamydia trachomatis in perinatal infection. Rev Infect Dis. 1983;5(4):713-9.

7. Jain A, Nag VL, Goel MM, Chandrawati, Chaturvedi UC. Adverse foetal outcome in specific IgM positive chlamydia trachomatis infection in pregnancy. Indian J Med Res. 1991;94:420-3.

8. Rastogi S, Kapur S. Chlamydia trachomatis infection in pregnancy risk factor for an adverse outcome. British J Biomed Sci. 1999;56:94-8.

9. Yashodhara P. Ranlakshami BA. Prevalence of specific IgM due to toxoplasma, rubella, cmv, chlamydia trachomatis infections during pregnancy. Indian J Med Microbiol. 2001;19(2):79-82.

10. Kishore J, Agarwal J. Seroanalysis of Chlamydia trachomatis and S-TORCH agents in women with recurrent spontaneous abortion. Indian J Pathol Microbiol. 2003;46940;684-7.

11. Avasthi K, Garg T, Gupta S, Grewal RK, Ram SA. Study of prevalence of Chlamydia trachomatis infection in women with first trimester pregnancy losses. Indian j. Pathol microbiol, 2003;jaw;46(1):133-6.

12. Richard L. Chlamydia trachomatis infection and pregnancy outcome. Am J Obstet Gynaecol. 1987; $156: 824$.

13. Paul VK, Singh M, Gupta U, Buckshee K, Bhargava VL, Takkar D, et al. Chlamydia trachomatis infection among pregnant women. Prevalence and prenatal importance. Natl Med J India. 1999;12(1):11-4.

Cite this article as: Pipal VR, Pipal R, Pipal D, Yadav S, Kamal M, Singariya G. Seroprevalence of Chlamydia trachomatis infection among pregnant women and their outcome. Int J Reprod Contracept Obstet Gynecol 2017;6:1016-20. 